\title{
La trata de personas: La codificación de un delito entorpecido por un lenguaje poco preciso
}

\section{Human trafficking: Coding a crime hampered by imprecise language}

\author{
Sofia Marina Lisé ${ }^{1}$ \\ Universidad de Buenos Aires - Argentina
}

Revista Derechos en Acción ISSN 2525-1678/ e-ISSN 2525-1686

Año 5/Nº 16 Invierno 2020 (21 junio a 20 septiembre), 493-532

DOl: https://doi.org/10.24215/25251678e432

Recibido: 01/04/2020

Aprobado: 15/09/2020

\section{Introducción}

Durante años, la trata de personas, a pesar de considerarse uno de los delitos más importantes y antiguos de la sociedad, ha sido pasada a un segundo plano en la codificación de nuestro código penal dejando como consecuencia una redacción inconsistente e incompleta. Y es que resulta incomprensible cómo es que un delito que atenta a los principales derechos humanos pueda ser pasado desapercibido a lo largo de la historia penal y social de nuestro país, y que haya comenzado a tomar relevancia la necesidad de un reparo social y legislativo recién en el siglo XXI.

Este trabajo tiene como finalidad exponer un breve análisis, aunque complejo y detallado, del delito de trata de personas desde una perspectiva lógica y comparativa que dilucide con

1 Estudiante de la Carrera de Abogacía en la Facultad de Derecho de la Universidad de Buenos Aires. 
mayor énfasis los problemas de codificación. Se introducirán los preceptos principales que identifican a todo ordenamiento jurídico y la diferencia entre ellos. Se demostrará la incompletitud del sistema normativo a lo largo de los años, con las continuas promulgaciones y derogaciones de las normas afectadas y cómo se llegó, luego del paso del tiempo, a una codificación asertiva que abarcase los diferentes tipos de comisión del delito. La falta de precisión en los términos utilizados en la codificación actual y las consecuencias que acarrea a la hora de dictar veredictos, y la necesidad de una aclaración internacional para darle fin a discusiones jurisprudenciales. Además, se pondrá en exposición una breve reflexión acerca de las diferencias entre la trata de personas y la prostitución, y la consideración de los jueces y legisladores a la hora de ponderar principios constitucionales.

\section{El delito de trata a través del tiempo}

\section{Consideraciones generales}

Como se ha mencionado supra, la trata de personas no es un delito contemporáneo. El tráfico de mujeres y su explotación sexual es uno de los atentados al honor, a la integridad física y a la dignidad humana más aberrantes y antiguos de la sociedad. Considero de vital importancia, antes de comenzar con el análisis normativo, introducir brevemente sus raíces para comprender, con el avance de la lectura, lo que será su futura codificación nacional.

"El término 'trata de blancas' fue acuñado por primera vez en 1902 para distinguir las conductas de tráfico de mujeres de tez blanca del oeste europeo de las del comercio de esclavos negros desarrollada en el Siglo XIX. Este nuevo negocio fue considerado como una nueva forma de dominación y de esclavitud en cuanto a la posición de dominio económico y la explotación capitalista de unos países sobre otros. Con el paso de los años, se ha ampliado el término de "explotación" incluyendo la trata laboral y sexual. Algunos sectores consideran que el delito ocupa el primer lugar como actividad lucrativa ilegal en el mundo. 
En nuestro país, el auge de la explotación sexual fue creciendo considerablemente a partir de mediados de los ochenta, con el continuo movimiento migratorio desde Europa y la demanda de prostitutas de los recién llegados. La compraventa de mujeres y niñas era justificada por el reditúo económico que dejaba el comercio y hasta incluso la explotación de estas fue considerada legal y reglamentada. En los ochenta funcionó un sistema conocido como prostitución reglamentada a partir del comienzo de las codificaciones municipales, que combinaba aspectos sanitarios, político-administrativos y policiales válidos tanto para prostitutas como para casas de tolerancia". ${ }^{2}$

No fue hasta 1913 con la famosa "Ley Palacios" que se produjo un cambio de paradigma a nivel legislativo en el Código Penal, donde, una vez más, Argentina se colocaba a la vanguardia de la defensa de los derechos humanos y se comenzaba, con vaivenes constantes, a regularse el delito de trata.

\section{El orden jurídico, la sistematización y las normas en el delito de trata}

Como bien se sabe y se expone con mayor claridad en el artículo "Sobre el concepto de orden jurídico" de Carlos E. Alchourrón y Eugenio Bulygin, las normas jurídicas no pueden ser interpretadas de una forma aislada, sino que deben ser tratadas en conjunto e interrelacionadas entre sí para su eficaz aplicación. Así lo explica Kelsen: "El derecho es un orden de la de conducta humana. Un 'orden' es un conjunto de normas (...) que tiene el tipo de unidad a que nos referimos cuando hablamos de un sistema. Es imposible captar la naturaleza del derecho si limitamos nuestra atención a una sola norma aislada. (...) Únicamente sobre la base de una clara comprensión de las relaciones que constituyen un ordenamiento jurídico, puede entenderse plenamente la naturaleza del derecho". ${ }^{3}$

\footnotetext{
2 BarittTa, "Trata de Personas", en Asociación Pensamiento Penal, 2008, p. 7 y 8.

3 Alchourrón \& Bulygin, "Sobre el concepto de Orden Jurídico", en Crítica: Revista Hispanoamericana de Filosofía, vol. 8, № 23, 1976, p. 3.
} 
Kelsen formula el precepto que refiere a que las normas no son aisladas, sino que forman parte de un conjunto, este conjunto lo denomina orden jurídico. Las relaciones de las normas son esenciales a la naturaleza del derecho, y este, como conjunto de normas que es, tiene el tipo de unidad de un sistema jurídico. Lo entendemos mejor en el siguiente cuadro explicativo:

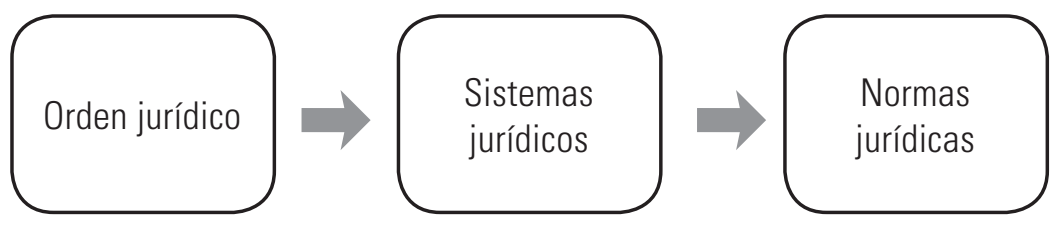

Para comprenderlo mejor, podemos identificar entonces al orden jurídico como la totalidad de normas válidas que pertenecen a un sistema jurídico en un momento dado, constituyendo su carácter determinable. ${ }^{4}$

Entendiendo a los sistemas jurídicos como el conjunto de normas jurídicas que integran el derecho de un país y constituyen el conjunto de todos los enunciados jurídicos (formando la base axiomática del sistema) contiene todas sus consecuencias, ya sean las expresamente formuladas o las derivadas. Y para que un sistema sea normativo, los enunciados de su base deben contener por lo menos algunos enunciados normativos o normas.

Concibiéndose como norma jurídica a un concepto amplio que abarca cualquier enunciado que figure en los textos que registran el derecho positivo, sea normativo o no; y que correlacionan ciertas circunstancias fácticas (casos) con determinadas consecuencias jurídicas (soluciones). ${ }^{5}$

Kelsen, Teoría General del Derecho y del Estado, 2ª Edición, México, 1958, p.3.

4 Pérez Porto \& Gardey. Definición de ordenamiento jurídico, 2011. Disponible en: https:// definicion.de/ordenamiento-juridico/

5 Cfr. Alchourrón \& Bulygin , op. cit., p. 5 y ss. 


\subsection{El concepto dinámico del orden jurídico}

Uno de los problemas que generó la definición de orden jurídico vino aparejado con los cambios normativos constantes que posee cualquier legislación a medida que los preceptos y necesidades sociales varían con el tiempo. Tal como sucedió con el delito de trata. Se ponía en discusión si el orden jurídico podía ser caracterizado como "dinámico" por el hecho de que se componía, precisamente, del conjunto de formulaciones normativas variables, es decir, de la secuencia de sistemas jurídicos. Esta discusión concluyó a que la doctrina pudiera terminar de dejar una clara distinción entre la diferenciación entre orden jurídico como secuencia de sistemas jurídicos y sistema jurídico como conjunto de normas.

Se entendió entonces que, "dado que el sistema está definido como un conjunto de normas, éstas permanecen fijas en el modelo: cualquier cambio de la base axiomática del sistema nos llevaría a otro sistema, distinto al anterior". ${ }^{6}$ En este sentido, el concepto de sistema jurídico (...) es estático y se encuentra referido a un punto temporal determinado, refiriéndose a que, con todo cambio provocado por los actos de creación o derogación de normas, el conjunto (sistema) deja de ser el mismo para convertirse en otro distinto.

Pero cuando los juristas hablan de sistema jurídico quieren dar cuenta del fenómeno del cambio: las normas jurídicas suelen cambiar con el transcurso del tiempo (algunas normas existentes son eliminadas, otras modificadas y se agregan nuevas), y la posibilidad de estos cambios temporales a nivel de cada norma analizada por separado determina el carácter dinámico del derecho.

Al asignarle al orden jurídico el sentido de una secuencia de conjuntos, hace que la unidad de la secuencia y la identidad del orden jurídico estén dadas por la identidad de los criterios

6 Cfr. Bulygin, "Sobre la regla de reconocimiento", en Derecho, filosofía y lenguaje-homenaje a Ambrosio L. Gioja, Buenos Aires, Astrea, 1976, p. 258 y ss. 
usados para la identificación de los conjuntos normativos pertenecientes a la secuencia. ${ }^{7}$ Esto expresa que el contenido del orden jurídico es también dinámico. Sólo si se modifican los criterios de identificación pierde el orden jurídico su identidad y es sustituido por otro nuevo orden.

\subsection{Identidad y estructura del orden jurídico}

Si se acepta la distinción entre orden jurídico y sistema jurídico, Caracciolo plantea dos problemas: Por un lado, es la cuestión de saber cuándo una secuencia de sistemas pertenece al mismo orden jurídico y cuándo se interrumpe y surge un nuevo orden jurídico, distinto del anterior. La segunda cuestión consiste en determinar el contenido de un sistema jurídico global (un caso particular) correspondiente a un determinado intervalo temporal.

Ambos problemas consisten en la determinación de los criterios de pertenencia de las normas al sistema (que, a su vez, determinan la estructura de este último) y de los sistemas al orden.

Caracciolo distingue dos criterios de pertenencia de las normas a los sistemas: a) Criterio de deducibilidad: una norma pertenece al sistema cuando es consecuencia lógica (deducible de) las normas pertenecientes al sistema; y b) Criterio de legalidad: una norma pertenece al sistema si ha sido creada (promulgada) por una autoridad competente del sistema. Lo que no sucede cuando se producen modificaciones legislativas producto de golpes de estado (quebrantamiento de nuestro ordenamiento jurídico en 1983 por cambios en la Constitución Nacional).

Estas dos relaciones determinan la estructura del sistema. Y se termina alegando que los jueces sólo son competentes para promulgar normas que son consecuencia lógica de las normas generales del sistema. Se diría entonces que el sistema jurídico (y por ende el orden jurídico), ha de ser reconstruido

7 Cfr. Alchourrón \& Bulygin, "Sobre el concepto de Orden Jurídico", op. cit., 395 y ss. 
de manera tal que su base sólo incluya normas generales y no normas individuales.

Pero estos dos criterios son manifiestamente insuficientes para dar cuenta de la pertenencia de todas las normas, porque presuponen que el sistema ya tiene normas, cuya pertenencia no depende de ninguno de los criterios anteriormente mencionados: las normas independientes.

Se entiende entonces que, todo orden jurídico tiene que originarse en un sistema de normas independientes producto del Sistema 0 (S0) que es el que dará origen a todas las normas pertenecerán a todos los sistemas subsiguientes de ese orden (siempre que no hayan sido derogadas o modificadas). Todos los sistemas pertenecientes a ese orden salvo el primero, se originan a partir del sistema inmediatamente anterior mediante adición de normas nuevas o por medio de la sustracción de normas.

En este sentido las normas independientes originarias constituyen la base del primer orden jurídico y el conjunto de estas será denominado por Kelsen como la primera constitución de ese orden jurídico. Entonces, todo orden jurídico tiene por definición una primera constitución. Esta puede ser modificada total o parcialmente dando lugar a nuevas constituciones derivadas, siempre que se establezca en ella algún procedimiento de reforma legal. La identidad del orden reposa en la continuidad de los sistemas que a él pertenecen, es decir, a la continuidad de la constitución, lo que no implica su inmutabilidad, sino la legalidad del cambio. Cuando la constitución es cambiada ilegalmente, conduce a una ruptura del orden jurídico y la nueva constitución dará origen a un nuevo orden.

\subsection{De la teoría a la trata}

Expuestos con brevedad los conceptos básicos del lenguaje del derecho en cuanto a las concepciones de codificación legislativa, será más sencillo explicar la introducción y derogación de las normas en una línea temporal del delito de trata y los sistemas jurídicos cambiantes. 
La incorporación de los derechos fundamentales que fueron restringiendo el delito de trata se fue dando de manera paulatina en nuestro ordenamiento jurídico y con las modificaciones que conllevó nuestra Carta Magna. Si bien fue afectada por seis reformas y un Estatuto Temporario, se mencionarán aquellas que impactaron directamente al delito en cuestión, dando un marco normativo más amplio a la protección de los derechos fundamentales.

Los derechos humanos se suelen distinguir en tres generaciones constitucionales. Las primeras normas independientes originarias de nuestro primer ordenamiento jurídico tomaron un carácter liberal, conteniendo, en su parte dogmática, los derechos humanos de primera generación: los principios civiles y políticos, vinculados con el principio de libertad (Constitución Nacional de 1853).

Luego, estos derechos se fueron ampliando a medida que la sociedad avanzaba al igual que la protección de sus ciudadanos. La segunda generación de derechos son los económicos, sociales y culturales, vinculados con el principio de igualdad (introducidos en nuestra Constitución Nacional en la reforma de 1949).

Por último, se llama a la tercera generación de derechos a aquellos surgidos en 1980 e incorporados en nuestra Constitución Nacional en la última reforma de 1994, vinculados con la solidaridad. Se comprendió en ella el reconocimiento constitucional de los Tratados Internacionales en los que argentina participó y/o adhirió y se vinculan con la solidaridad y cooperación internacional. En esta generación se incluyen derechos heterogéneos como el derecho a la paz y a la calidad de vida.

Podemos ver entonces cómo las bases originales del primer ordenamiento jurídico fueron cambiando al incorporar nuevos derechos y así crearon nuevas modificaciones en las bases de las normas independientes. Todos estos cambios fueron realizados legalmente mediante las primeras normas independientes del S0, demostrando que, a pesar de que las normativas 
internas cambiaban constantemente, promulgándose nuevas, y consecuentemente también lo hicieron los sistemas que estas componían, no lo hizo el orden jurídico precisamente por su carácter dinámico. Es así como un mismo ordenamiento jurídico tiene infinitos sistemas a medida que se derogan o ampliaban las normas.

Dicho todo esto, veamos un ejemplo:

La primera reglamentación contra la trata fue la ya mencionada "Ley Palacios" (Ley 9.143, promulgada en 1913), de ahora en más la llamaremos N 2. La misma rezaba por una modificación en el Código Penal para reprimir a quienes promoviesen o facilitasen la corrupción o la prostitución de mujeres -mayores y menores de edad-, y se consideraba coautores del delito a los dueños de los prostíbulos. Esta normativa pone un freno al Reglamento de Prostíbulos de Buenos Aires N 1, de enero de 1875 que no prohibía la explotación sexual, sino que la restringía: "No podrá haber en los prostíbulos mujeres menores de 18 años, salvo que se hubieren entregado a la prostitución con anterioridad".

En 1936 surge la Creación del Instituto de Profilaxis de las Enfermedades Venéreas, $N 3$, por medio de la Ley 12.331. Esta no sólo sanciona a quien explota un establecimiento donde se ejerce la prostitución, complementando la Ley Palacios, sino también a quien lo hace con uno donde se incita a ella, hipótesis dada en el caso de autos.

Años más tarde, en 1944, el Decreto Presidencial 10.638, N 4 modifica y amplía los artículos 17 Y 15 de la ley 12.331 (N 3).

El artículo 15 establece que: "queda prohibido en toda la República el establecimiento de casas o locales donde se ejerza la prostitución, o se incite a ella". Asimismo, el artículo 17 indica que: "los que sostengan, administren o regenteen, ostensible o encubiertamente casas de tolerancia serán castigados con una multa de mil pesos moneda nacional. En caso de reincidencia sufrirán prisión de uno a tres años, la que no podrá aplicarse en calidad de condicional. Si fuesen ciudadanos por naturalización, 
la pena tendrá la accesoria de pérdida de la carta de ciudadanía y expulsión del país una vez cumplida la condena; expulsión que se aplicará, asimismo, si el penado fuese extranjero.”.

En 1965, la Ley 16.666, N 5, abroga el decreto ley 10638/44 referido a la represión de la trata de blancas, ratificado por la ley 12.912 y toda otra disposición que se oponga al mismo. En otras palabras, este decreto derogaba las modificaciones ampliatorias de 1944 respecto de los artículos 15 y 17, y se hace un retroceso legislativo a nivel penal a pesar de los convenios internacionales que comenzaban a tomar cada vez más fuerza.

Con estas primeras leyes, podemos ver brevemente las modificaciones constantes de los sistemas jurídicos producto de sus normativas. La promulgación de la ley $\mathrm{N} 2$ provocó la derogación de la norma formulada $\mathrm{N}$ 1, al derogarse una determinada norma, para colocar en su lugar otra norma diferente se crea un nuevo sistema jurídico (que llamaremos de ahora en más S 2). Lo que se deroga aquí es la norma y todas las normas que se derivan de ella y las que ayudaron a crearla. No se trata de una relación temporal. La derogación es unívoca: la eliminación de una norma determinada de un sistema determinado conduce a otro sistema, también determinado. En este caso, se reemplazó una norma por otra completamente diferente.

La incorporación de N 3 no provocó la derogación de N 2, sino que se introdujo al conjunto de implicancias que esta última promulgaba, complementándose mutuamente. Es así como:

S 2 > conjunto de normas producto de la incorporación de $\mathrm{N} 2$ S 2 (conjunto de normas de N 2) + N 3 (nueva norma) つ nuevo sistema jurídico $\mathrm{N} 3$

Entonces, la promulgación de una nueva norma provoca en el nuevo sistema jurídico todas las consecuencias del sistema jurídico anterior, las consecuencias normativas de la nueva norma y las consecuencias normativas relacionadas entre las dos primeras normas. El presente gráfico y sus respectivos números correspondientes a los sistemas es meramente 
ejemplificativo para lograr explicar con mayor claridad el avance y la modificación de los sistemas. ${ }^{8}$

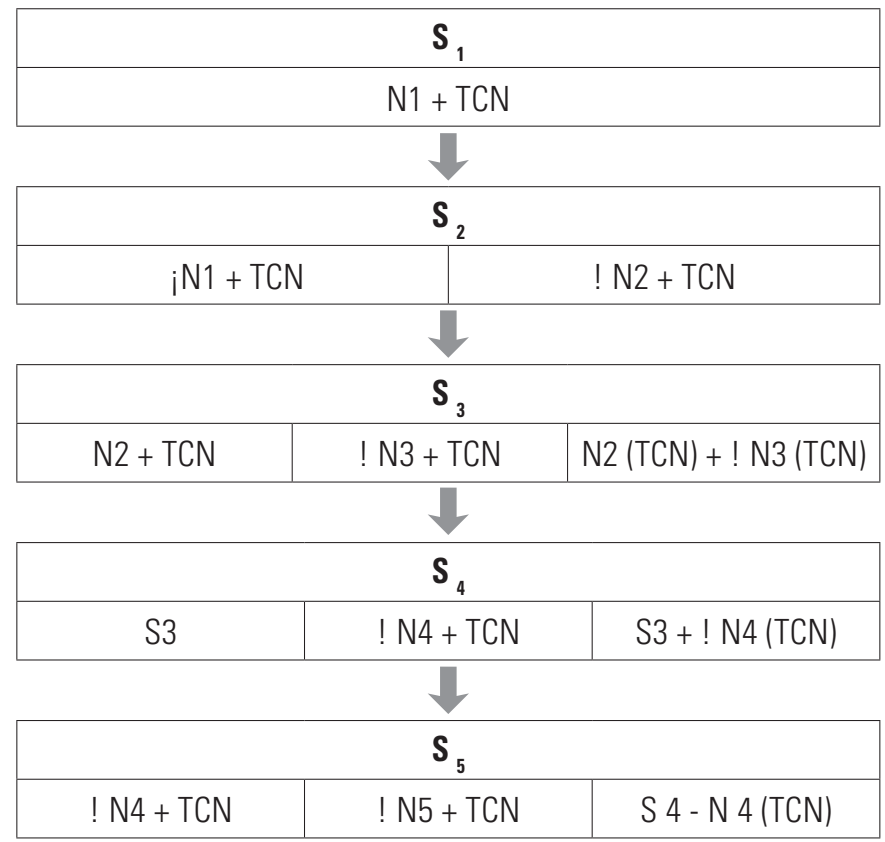

\begin{tabular}{|c|c|}
\hline \multicolumn{2}{|c|}{ Símbolos y significados } \\
\hline $\mathbf{S}$ & Sistema \\
\hline $\mathbf{N}$ & Norma \\
\hline$!$ & Promulgación \\
\hline$\dot{\mathrm{d}}$ & Derogación \\
\hline TCN & Todas sus consecuencias normativas \\
\hline
\end{tabular}

A raíz de lo brevemente ejemplificado se entiende entonces que los sistemas jurídicos no tienen existencia continua, son

8 Cabe resaltar que se denomina $S_{1}$ y no $S_{0}$ porque, a pesar de ser la primera ley reglamentaria en cuanto a la explotación sexual, su promulgación no se trata de una norma soberana. Es decir que, para su entrada en vigencia fue dependiente del criterio de legalidad. 
relativos a un momento temporal dado. Este tiempo se caracteriza por ser discontinuo, discreto y los momentos temporales están dados por los actos de promulgación y derogación de las normas. Todo acto que crea una nueva norma o deroga una norma existente determina un momento nuevo y con ello un sistema nuevo.

\section{Las lagunas jurídicas y el delito de trata}

Como ya se ha mencionado, la codificación del delito de trata no fue estable. Durante años, por razones políticas, económicas y sociales, fue difícil incluso que se lograra incorporar su normativa en nuestra legislación.

Siguiendo el historial normativo de los puntos anteriores y con los vaivenes constantes entre promulgación y derogación de artículos, en 1999, la Ley 25.087 incluye el artículo 127 ter y complementa la Ley 21.388. El mismo dispone que "El que promoviere o facilitare la entrada o salida del país de una persona mayor de 18 años para que ejerza la prostitución mediando engaño, violencia, amenaza, abuso de autoridad o cualquier otro medio de intimidación o coerción, será reprimido con reclusión o prisión de tres a seis años.".

Pese a que la codificación de 1999 constituyó un gran avance en la materia legislativa de la trata, y que los demás artículos modificados en la misma ley fueron asertivos, no se la puede terminar de definir como una normativa completa. La falta de completitud, la incoherencia y la indeterminación pertenecen a defectos lógicos; y en lo que respecta a la redacción del delito de trata incluso luego de las modificaciones de la Ley 25.087, se puede decir que una de las materias principales quedó desprotegida: nada se dice del sujeto que promoviere o facilitare el traslado interno de las víctimas de trata. ¿Qué sucede en el caso de que quien promueve o facilite la entrada o salida del país sea una persona y quien las traslade de un punto a otro dentro del país sea otro? En este caso, el sujeto quedaría libre de culpa y pena a miras de la interpretación normativa. 
El problema de la completitud del sistema jurídico es conocido en la literatura jurídica como el problema de las lagunas del derecho, y hace referencia al hecho de que una acción no esté regulada por el sistema jurídico en cuestión y lo vuelva incompleto. Como bien explican Alchourrón y Bulygin se dice que: "El concepto de laguna normativa puede ser definido en términos de la determinación normativa. Una acción p (perteneciente a una determinada clase de acciones $\mathrm{H}$ ) está normativamente determinada en el sistema $\mathrm{S}$ si, y sólo si, p está permitida o prohibida en $\mathrm{S}$. Cuando una de las acciones de la clase $\mathrm{H}$ no está determinada en $\mathrm{S}$, tenemos una laguna y el sistema $\mathrm{S}$ es incompleto de H. Sólo cuando todas las acciones de H están determinadas, el sistema $\mathrm{S}$ es completo con relación a $\mathrm{H}$. La completitud (laguna) es, por lo tanto, un concepto relacional".?

Se dice entonces que una laguna es una situación no regulada que afecta la operatividad del sistema, y la dificultad de esta sólo puede ser superada mediante el agregado de una nueva norma al sistema. La cuestión acerca de la existencia de las lagunas es siempre relativa a un sistema normativo. La idea de completitud requiere que todos los casos tengan una solución y que todas las soluciones correlacionadas con los casos sean completas, en el sentido de que todas las acciones posibles estén normativamente determinadas.

Ahora bien, ¿cómo se logra subsanar una laguna en el sistema jurídico? Como los jueces no pueden dejar de sentenciar, aún en los casos de ausencia de normas, corresponde modificar el sistema y esto se logra completándolo mediante la modificación o invención de una nueva norma. Esta nueva norma deberá suplir cualquier tipo de ausencia casuística y a la vez haber sido la más adecuada para ser incorporada.

A pesar de que existan varias clases de teorías para suplir esta carencia, la que ha tomado más peso a lo largo de los años es la teoría de la argumentación jurídica, la cual sostiene

9 Cfr. Alchourrón \& Bulygin, "Sobre el concepto de Orden Jurídico", op. cit. p. 17 y ss. 
que ante un caso difícil es posible crear una norma que sea la más adecuada si se cumplen determinados requisitos y puede crearse a partir del material preexistente. Esta resolución deberá cumplir con los requisitos de consistencia y coberencia en relación con el sistema jurídico en cuestión.

Será una decisión consistente cuando se basa en premisas normativas que no entran en contradicción con normas válidamente establecidas.

Y será coherente si la norma en que se basa es coherente en relación a los principios del sistema normativo en cuestión, identificándolos previamente.

Una vez hecho esto, se formularán dos tipos de normas: una mínima (es la norma menos beneficiosa posible dentro de los límites de la coherencia del sistema) y una máxima (la norma más beneficiosa posible dentro de los límites de la coherencia). Ninguna de las dos normas pertenece al sistema, son una creación de la ciencia jurídica a partir del sistema que posee la laguna, en base a la tesis de coherencia. Solamente constituyen las posibles soluciones que se pueden dar para completar el sistema y se deberá elegir entre ellas o crear una intermedia si ninguna resulta favorable.

Por tanto, el juez intentará suplir la laguna decidiendo la situación planteada de forma justa, e intentará justificar su decisión destacando los puntos del caso que considere relevantes. Los operadores del derecho juegan un papel emprendedor en esta cuestión: no van a crear nuevas normas que eliminen las lagunas, pero sí pueden accionar en la búsqueda de su solución. Crear una norma no es lo mismo que integrar el Derecho, lo primero es responsabilidad del órgano legislativo, y la segunda cuestión es menester de los juristas, donde el juez es uno de los principales en esta ardua labor.

Volviendo al tema en cuestión, durante los años que transcurrieron entre el artículo 127 ter y una nueva codificación, ante el delito de trata interna los jueces fueron los encargados en sentar jurisprudencia. 
La incompletitud de esta normativa quedó resuelta definitivamente recién en el año 2008 con la incorporación de la Ley 26.364 sobre Prevención y Sanción De La Trata De Personas y Asistencia a sus Víctimas. En su artículo 10 reza la modificación del Código Penal: Incorpórese como artículo 145 bis del Código Penal, el siguiente: artículo 145 bis: "El que captare, transportare o trasladare, dentro del país o desde o hacia el exterior, acogiere o recibiere personas mayores de dieciocho años de edad, cuando mediare engaño, fraude, violencia, amenaza o cualquier otro medio de intimidación o coerción, abuso de autoridad o de una situación de vulnerabilidad, concesión o recepción de pagos o beneficios para obtener el consentimiento de una persona que tenga autoridad sobre la víctima, con fines de explotación, será reprimido con prisión de TRES (3) a SEIS (6) años.”.

De esta forma, el vacío legislativo quedó remediado por una nueva incorporación normativa por parte del legislador, comprendiendo como sujetos activos también a aquellos sujetos que intervinieron en el traslado interno de las víctimas. Se cambia la base axiológica del sistema mediante el principio de legalidad y, por ende, se conforma uno nuevo.

\section{Nueva codificación, mismos problemas lingüísticos}

\section{La "situación de vulnerabilidad" y la vaguedad}

La incorporación del delito de trata al Código Penal Argentino era una deuda que tenía la República Argentina al ser nuestro país signatario de los principales Tratados Internacionales de protección a las víctimas de trata.

El delito se encuentra en el Libro II, Título V del Código Penal y fue introducido por la Ley 26.364 en 2008 y modificado por la Ley 26.842 en 2012, quedando tipificado de la siguiente manera: Artículo 127: "Será reprimido con prisión de cuatro (4) a seis (6) años, el que explotare económicamente el ejercicio de la prostitución de una persona, aunque mediare el consentimiento de la víctima.”. 
La pena será de cinco (5) a diez (10) años de prisión, si concurriere alguna de las siguientes circunstancias:

1. Mediare engaño, fraude, violencia, amenaza o cualquier otro medio de intimidación o coerción, abuso de autoridad o de una situación de vulnerabilidad, o concesión o recepción de pagos o beneficios para obtener el consentimiento de una persona que tenga autoridad sobre la víctima.

2. El autor fuere ascendiente, descendiente, cónyuge, afín en línea recta, colateral o conviviente, tutor, curador, autoridad o ministro de cualquier culto reconocido o no, o encargado de la educación o de la guarda de la víctima.

3. El autor fuere funcionario público o miembro de una fuerza de seguridad, policial o penitenciaria.

Cuando la víctima fuere menor de dieciocho (18) años la pena será de diez (10) a quince (15) años de prisión.

Artículo 145 bis: Será reprimido con prisión de cuatro (4) a ocho (8) años, el que ofreciere, captare, trasladare, recibiere o acogiere personas con fines de explotación, ya sea dentro del territorio nacional, como desde o hacia otros países, aunque mediare el consentimiento de la víctima.

Artículo 145 ter: En los supuestos del artículo 145 bis la pena será de cinco (5) a diez (10) años de prisión, cuando:

1. Mediare engaño, fraude, violencia, amenaza o cualquier otro medio de intimidación o coerción, abuso de autoridad o de una situación de vulnerabilidad, o concesión o recepción de pagos o beneficios para obtener el consentimiento de una persona que tenga autoridad sobre la víctima.

2. La víctima estuviere embarazada, o fuere mayor de setenta (70) años.

3. La víctima fuera una persona discapacitada, enferma o que no pueda valerse por sí misma.

4. Las víctimas fueren tres (3) o más.

5. En la comisión del delito participaren tres (3) o más personas. 
6. El autor fuere ascendiente, descendiente, cónyuge, afín en línea recta, colateral o conviviente, tutor, curador, autoridad o ministro de cualquier culto reconocido o no, o encargado de la educación o de la guarda de la víctima.

7. El autor fuere funcionario público o miembro de una fuerza de seguridad, policial o penitenciaria.

Cuando se lograra consumar la explotación de la víctima objeto del delito de trata de personas la pena será de ocho (8) a doce (12) años de prisión.

Cuando la víctima fuere menor de dieciocho (18) años la pena será de diez (10) a quince (15) años de prisión.

A pesar de que, en comparación con las normativas de décadas anteriores, la actual abarca todas las acciones que pueden derivar al delito de trata de personas, y si no lo hace, con el carácter constitucional que se le fue conferido a los Tratados Internacionales luego de la reforma constitucional de 1994, estos pueden suplir las carencias, es imposible dejar de obviar la terminología poco precisa que se le dio al agravante de "situación de vulnerabilidad".

El concepto de "situación de vulnerabilidad" fue introducido en 2008 con la ley de "Prevención y Sanción de la Trata de Personas y Asistencia a sus víctimas" con la modificación a nuestro Código Penal, producto de la adhesión al Protocolo de las Naciones Unidas para Prevenir, Reprimir y Sancionar la Trata de Personas, Especialmente Mujeres y Niños, uno de las tres Protocolos de Palermo de la Convención de las Naciones Unidas contra la Delincuencia Organizada Transnacional.

El Protocolo, y su definición de trata de personas, han sido aceptados ampliamente por los Estados y la comunidad internacional. No obstante, se ha hecho evidente que sigue habiendo dudas acerca de ciertos aspectos de esa definición, así como de su aplicación al derecho penal nacional. En particular, han surgido dudas relativas a los aspectos de la definición que no se describen en otras partes del derecho internacional ni se conocen de manera general en los principales sistemas jurídicos del 
mundo. La existencia de esas dudas supone que los parámetros acerca de lo que constituye "trata" aún no están consolidados.

Y precisamente, una de estas dudas versa sobre la definición de "situación de vulnerabilidad", un concepto muy abarcativo y poco claro que constituyó un problema de vaguedad en el sistema jurídico, no solo argentino, sino mundial. Dejando abiertas muchas puertas a consideración de la subjetividad de los jueces.

Cuando hablamos de vaguedad nos referimos a un problema del lenguaje en general que, al igual que se mencionó anteriormente con el problema de las lagunas, afecta al derecho y a su aplicación.

"Las palabras y frases que son vagas están, en consecuencia, desprovistas de precisión". ${ }^{10}$

En la vaguedad, el problema se presenta al nivel de subsunción de un caso individual en el caso genérico establecido por una norma ya identificada. Es decir, la vaguedad se presenta en el nivel de la aplicación de las normas a los casos concretos. "Se dice que un término es vago cuando existen casos individuales para los que no puede decirse con carácter definitivo si el término en cuestión puede o no aplicase a ellos". ${ }^{11}$ Aun cuando existiese plena certeza sobre los hechos, es factible que existan dudas sobre si una palabra de clase se aplica a los hechos probados.

Sucede esto entonces con el concepto de "situación de vulnerabilidad" mencionado supra, una vez incorporado en nuestro código penal y a medida que los jueces debían analizar y fallar sobre los casos presentados, el campo en que aplicaban la situación de vulnerabilidad se tornaba cada vez más impreciso, debiendo ser analizado según la particularidad de cada situación sin tener un consenso definitivo sobre el mismo.

Se pueden distinguir diversas formas de vaguedad, destacándose: la vaguedad en términos polares y la vaguedad combinatoria.

10 Hospers, 1976, p. 93, en Alonso, Interpretación de las normas y derecho penal, Edit. Del Puerto, Buenos Aires, 2006, p. 59.

11 Alston, p.125 y ss., en Alonso, ídem. 
El problema lingüístico de la "situación de vulnerabilidad" se encuadra dentro del segundo tipo de vaguedad: la combinatoria. La misma se "se deriva en torno a qué combinación de condiciones es necesaria o suficiente para la aplicación del término y a menudo tenemos este tipo de vaguedad cuando hay una pluralidad de condiciones relevantes". ${ }^{12}$

En Interpretación de las normas y derecho penal, ${ }^{13}$ se menciona uno de los ejemplos dados por Alston para poner en claridad este tipo de vaguedad. El doctrinario pone en juego el concepto de la palabra "religión", enumerando nueve rasgos que se suelen atribuir para su uso, las dudas versarán aquí cuando alguno de estos nueve rasgos o, aunque sea uno de ellos no se presente en el caso a analizar. ¿Se podrá entonces utilizar la palabra "religión" en esa situación determinada?

Otro de los ejemplos planteados es aquel del artículo 129 del Código Penal cuando se habla de "exhibiciones obscenas": "Será reprimido con multa de mil a quince mil pesos al que ejecutare o hiciese ejecutar por otros actos de exhibiciones obscenas expuestas a ser vistas involuntariamente por terceros".

Este tipo de noción, al igual que el de "situación de vulnerabilidad" dependerá de muchas variables, existiendo diferentes concepciones entre diferentes culturas, épocas y hablantes, sean o no de la misma comunidad o país. Si bien a nivel del lenguaje ordinario el problema de la vaguedad no suele ser de mayor importancia, sí lo es en el ámbito del lenguaje normativo, donde lo más seguro es que los jueces no tengan la misma concepción a lo que "situación de vulnerabilidad" se refiere a la hora de analizar y dictar resoluciones; lo que generaría jurisprudencia contradictoria respecto de las mismas situaciones y, al ser un delito que su consecuencia es la pena, se pone en juego principalmente el principio jurídico de la libertad de quien se está juzgando en el proceso.

\footnotetext{
12 Alston, p.130, en Alonso, ibídem, p. 60.

13 Alonso, ídem.
} 
Ahora bien, ¿cómo se solución a este problema del lenguaje en el derecho?

\subsection{La interpretación subjetiva}

Como se ha mencionado, una de las estrategias para resolver los problemas de indeterminación semántica es la "interpretación subjetiva", la cual suele ser enfrentada al modelo de la literalidad ("o interpretación objetiva").

"Según esta concepción, el derecho es un medio del que el legislador se sirve para alcanzar unos fines y para promover unos determinados valores. (...) En consecuencia, el juez no puede contentarse con una simple deducción a partir de textos legales. Debe remontarse desde el texto a la intención que permitió definir la voluntad del legislador, e interpretar el texto conforme a aquella voluntad. Pues lo que cuenta, ante todo, es el fin perseguido, el espíritu más que la letra de la ley". ${ }^{14}$

Los defensores de la interpretación subjetiva se acatan diciendo que cuando el modelo de la literalidad es insuficiente para identificar las normas que conforman la ley, la remisión a la exposición de motivos es procedente ya que, si bien la misma puede padecer de problemas de indeterminación semántica, también es factible que pueda brindar parámetros para resolver la indeterminación de las disposiciones legislativas mediante el análisis de tres fuentes principales: la exposición de motivos de una ley; las intenciones del legislador y los principios jurídicos.

Con la incorporación del concepto de "situación de vulnerabilidad" encuadrado como uno de los agravantes en la codificación del delito de trata, se trajeron aparejadas dos interpretaciones respecto de este concepto por parte de los jueces: una interpretación conservadora y una interpretación amplia. Algunos jueces consideraron más la condición de "situación de vulnerabilidad" que hacía al sujeto activo comportarse de esa manera y realizar actos ilegales debido a condiciones de

14 Perelman, 1979, pp. 74-75, en Alonso, op. cit. p. 66. 
pobreza y desigualdad social o lo limitaban a situaciones muy concretas; y otros, por el contrario, y a razón de lo que reza la norma, centraban las condiciones de vulnerabilidad que tenía la víctima a la hora de haber sido privada de su libertad y utilizada como objeto de explotación sexual, ampliando el campo considerativo respecto de las mismas.

Veamos dos claros ejemplos jurisprudenciales:

Vulnerabilidad. Valoración de factores económicos y sociales. Alcance restrictivo del concepto de vulnerabilidad limitado a nacionalidad y libertad física. CNCN, Sala II, causa FCB 1200214/12 "Barey Fabio Ricardo s/recurso de casación", registro. 1702. "El a quo desarrollo de modo arbitrario el concepto de vulnerabilidad (...) el Tribunal descartó la condición social y económica como indicador de vulnerabilidad-repito, conforme las Reglas de Brasilia que él mismo cita-vaciando de contenido dicho elemento objetivo del delito de trata de personas, limitándolo exclusivamente a las siguientes variables: nacionalidad y libertad física de las víctimas... De este modo consideró que la ausencia de menoscabo a la libertad física (entendemos por libertad el becho de que habian acordado un horario de trabajo, podian faltar (...) y al finalizar la jornada cobraban la parte que les correspondian, por las copas y por los pases y se retiraban a sus domicilios) equivale a ausencia de situación de vulnerabilidad, y por ende, atipicidad del delito de trata de personas reprochado a los acusados... Si bien las mujeres entrevistadas manifestaron su 'opción' de trabajar en los lugares allanados, en todos los relatos reitera la existencia previa de una situación de vulnerabilidad que resultó condicionante para que las mujeres fueran ingresadas al circuito prostibulario".

En este caso, la subjetividad del juez a la hora de fallar fue limitada solamente en dos variables: la nacionalidad y la libertad física. Teniendo así una concepción conservadora sobre el concepto.

Alcances del concepto de vulnerabilidad. CNCN, Sala II, causa FCB 1200214/12 "Barey Fabio Ricardo s/recurso de 
casación", registro. 1702. "El estado de vulnerabilidad no refiere únicamente a aspectos de privación económica, sino también a la dificultad de acceso al sistema educativo, de salud o a los derechos sexuales y reproductivos, que no hacen más que profundizar la situación de vulnerabilidad que genera la privación económica. Con excepción a una sola mujer, todas tendrían varios hijos y serían las únicas o principales responsables de la manutención y crianza de estos, muchas de ellas habiendo sido madres durante la adolescencia. Estas circunstancias debieron necesariamente ser evaluadas al momento de determinar si las mujeres que ejercían la prostitución en los locales investigados estaban en una situación de vulnerabilidad que podía llegar a ser objeto de abuso por parte de los imputados. Cuestión que el tribunal de mérito omitió dando un alcance al concepto de vulnerabilidad que no se condice con los fines de la Ley 26364, ni con la política del estado argentino para prevenir, investigar y sancionar este tipo de violencia contra las mujeres".

En este segundo caso, el concepto de "situación de vulnerabilidad" se utiliza a la hora de dictar sentencia con la finalidad abarcativa que le confirieron los organismos internacionales.

Se puede ver entonces, que incluso aunque las tres fuentes jurídicas en los que se basa la interpretación subjetiva a la hora de intentar esclarecer conceptos sean iguales para todos los juristas, estos fallarán según su concepción sin criterios estables y preestablecidos que sirvan de base para respuestas asertivas y uniformes. Es entonces que la utilización aislada de los recursos de la "interpretación subjetiva" puede llegar a conclusiones incompatibles entre sí según las opiniones de diferentes juristas.

Se deja ver que el modelo de la interpretación subjetiva conlleva entonces a referencias difusas y equívocas respecto de la fuente jurídica a la que se recurre.

Ahora bien, visto y considerando que ninguna de las dos soluciones anteriores parecen asertivas, ¿qué criterios deberían adoptarse para superar esta vaguedad? Según Alston, la vaguedad puede restringirse mediante formulaciones legislativas 
específicas o aclaratorias. Veremos la solución que se le dio a la controversia aquí planteada a continuación.

\subsection{El documento temático que le puso fin a la indeterminación}

Debido a que la introducción del concepto de "situación de vulnerabilidad" como agravante en el delito de trata no generó controversias únicamente en los tribunales argentinos, sino que también afectó a las interpretaciones y sentencias de muchos otros países, la solución de los organismos internacionales fue crear un documento temático específicamente referido a la situación de vulnerabilidad para dar fin a las controversias.

De este modo, la vaguedad legislativa quedó zanjada a través de un documento complementario internacional de carácter constitucional. En el documento final de "La cumbre judicial sobre el acceso a la justicia" celebrada en el Brasil en 2008 figura la siguiente definición del concepto de vulnerabilidad:

"Se consideran en condición de vulnerabilidad aquellas personas que, por razón de su edad, género, estado físico o mental, o por circunstancias sociales, económicas, étnicas y/o culturales, encuentran especiales dificultades para ejercitar con plenitud ante el sistema de justicia los derechos reconocidos por el ordenamiento jurídico. Podrán constituir causas de la vulnerabilidad, entre otras, la siguientes: la edad, la discapacidad, la pertenencia a comunidades indígenas o a minorías, la victimización, la migración y el desplazamiento interno, la pobreza, el género y la privación de la libertad. La concreta determinación de las personas en condición de vulnerabilidad en cada país dependerá de sus características específicas, o incluso de su nivel de desarrollo social y económico"15.

Con esta definición específica y quedando aclarada cualquier duda que se tuviera respecto a qué casos se debía aplicar el concepto de "situación de vulnerabilidad", no pudiendo

\footnotetext{
15 XIV Cumbre Judicial Iberoamericana, 100 Reglas de Brasilia sobre Acceso a la Justicia de las Personas en Condición de Vulnerabilidad, Brasilia, 2008, p. 5.
} 
obviar, que continúa perteneciendo a un concepto genérico y que sus especificaciones deben ser aplicadas a cada caso en particular, los jueces, luego de esta aclaración internacional, no deberían escapar de esta definición.

Véanse a continuación extractos de fallos en los que se tomó la consideración de las Reglas de Brasilia y disposiciones subsiguientes también provenientes de organismos internacionales con carácter constitucional que decidieron expedirse sobre el tema en cuestión para una mayor claridad y homogeneidad a la hora de dictar las resoluciones por los Estados partes:

Vulnerabilidad. Acordada nro.5/2009 CSJN (voto del Juez Gustavo Hornos). CNCP, Sala IV, causa 1735/13 "Cañete Dario y otros s/recurso de casación”, rta.30/12/14, registro nro.3156/14. “ (...) Corresponde recordar la condición de vulnerabilidad en que se hallaba J.N.C., que ha sido definida en las 'Reglas de Brasilia sobre el acceso a la Justicia de las personas en condición de vulnerabilidad' (Cumbre Judicial Iberoamericana de Brasilia, marzo de 2008), a las que adbirió la Corte Suprema de Justicia de la Nación, mediante el dictado de la Acordada Nro. 5/2009". En dicha acordada el Supremo Tribunal estableció que "se consideran en condición de vulnerabilidad aquella víctima del delito que tenga una relevante limitación para evitar o mitigar los daños y perjuicios derivados de la infracción penal o de su contacto con el sistema de justicia, o para afrontar los riesgos de sufrir una nueva victimización. La vulnerabilidad puede proceder de sus propias características personales o bien de las circunstancias de la infracción penal. Destacan a estos efectos, entre otras víctimas, las personas menores de edad, las víctimas de violencia doméstica o intrafamiliar, las víctimas de delitos sexuales, los adultos mayores, así como los familiares de víctimas de muerte violenta".

Abuso de una situación de vulnerabilidad. Nota orientativa de la UNODOC. CNCP, Sala IV, Causa nro. CFP 2613/2012, "Orellana Condo, Olga s/ recurso de casación", rta el 7 de julio de 2015, reg. nro. 1308/2015.4. " (...) Corresponde señalar que 
el análisis probatorio debe ser realizado desde la perspectiva que ha propuesto la Oficina de las Naciones Unidas contra la Droga y el Delito en cuanto sostuvo que la situación de vulnerabilidad hace referencia a una situación en la que la persona es más propensa a brindar su conformidad a ser explotado, y el abuso de esa situación ocurre cuando el autor usa intencionalmente o se aprovecha de la vulnerabilidad de la víctima para captarla, transportarla, trasladarla, acogerla o recibirla con el fin de explotarla, de modo que la persona crea que someterse a la voluntad del abusador es la única alternativa real o aceptable que dispone y que resulte razonable que crea eso a la luz de la situación (cfr. 'Nota orientativa sobre el concepto de 'abuso de una situación de vulnerabilidad' como medio para cometer el delito de trata de personas, expresado en el artículo 3 del Protocolo para prevenir, reprimir y sancionar la trata de personas, especialmente mujeres y niños, que complementa la Convención de las Naciones Unidas contra la Delincuencia Organizada Transnacional') (del voto del doctor Gustavo Hornos)".

En conclusión, posiblemente es imposible eliminar del todo la vaguedad de los conceptos legislativos, aunque siempre cabe hacer algo para reducirla a límites tolerables y esto corresponde a la labor de los juristas teóricos y de los legisladores. Identificarla y buscar la solución legislativa más endeble al problema suscitado hace que la legislación se torne más segura y justa a la hora de su aplicación, intentando no dejar un margen más amplio de lo normal a la hora del análisis judicial.

\section{La prostitución, la trata y los principios constitucionales}

\section{El trabajo sexual y el consentimiento}

Se ha visto en las primeras páginas del presente trabajo que la codificación del delito de trata de personas fue una deuda social que mantuvo nuestra legislación durante muchos años, se debe resaltar que el principal objeto de esta siempre fue la de penar a aquellos sujetos que se aprovechaban de ella obteniendo 
un reditúo a cambio, mientras afectaban los principios inherentes y más importantes del ser humano por medio de la captura, retención y explotación contra su voluntad.

Y si bien se entiende que lo que pretende prevenir en los artículos referentes a la trata, es el consentimiento de una víctima que realmente ha sido engañada y no tiene la menor intención de dedicarse a la actividad o que es violentada física o psicológicamente; no puede dejar de obviarse, que, además de estar penado el delito de trata, se pena a quien obtenga un beneficio en el ejercicio de la prostitución de un tercero. En nuestra legislación se deja en claro en el artículo 127, que será reprimido el que explotare económicamente el ejercicio de la prostitución de una persona, aunque mediare el consentimiento de la víctima.

Limitando, indirectamente, el ejercicio libre de la prostitución al considerar como sujeto activo a quien obtenga un beneficio (ya sea económico como sexual) de la misma. Poniendo al mismo nivel (y hasta incluso considerándola de la misma manera) a la trata y a la prostitución, en el artículo mencionado. Si bien el delito mismo de la prostitución no se encuentra penado, sí lo está indirectamente cuando se reza que se condenará al "sujeto activo" o a quien la facilite (entiéndase como los dueños de casas de prostitución).

Y es que considerándolo con un panorama algo prehistórico y lleno de prejuzgamientos sociales, a primera vista creemos que estamos frente a una normativa correcta al creer que quien presta consentimiento para la explotación sexual de su propio cuerpo no es consciente plenamente de lo que hace. Pero ¿es verdaderamente así? ¿Podemos penar o prohibir indirectamente el ejercicio de la elección libre sobre las decisiones que terceros tienen sobre sus cuerpos y lo que hacen con ellos? ¿A caso esta normativa no interfiere también con principios constitucionales tales como la libertad sexual, personal y el derecho a la privacidad? ¿A caso no tenemos todos el mismo derecho a elegir de qué trabajar? ¿Sobre qué bases se juzga que un trabajo, realizado con consentimiento, es digno o indigno de realizar? ¿Cuántos de 
ellos realizados hoy día, mediando también la explotación del propio cuerpo, sea físico o psíquico, y poniendo en riesgo el contagio de enfermedades o el peligro a la vida, no son penados, sino que regulados normativamente?

Se ha definido el bien jurídico libertad como “... la facultad de todo individuo de ejecutar sus propias decisiones, sea que éstas se refieran a desempeñar una determinada actividad, o a no realizarla, o a impedir que terceros invadan un ámbito de intimidad reconocido constitucionalmente... la libertad se manifiesta no sólo como un derecho de hacer o no hacer; sino también como un derecho a impedir que otros hagan...". ${ }^{16}$

No se puede dejar de obviar que esta restricción y consideración acerca del consentimiento del propio cuerpo para la explotación sexual también se encuentra codificada en los instrumentos internacionales, tomando los Estados un rol de "padres" a la hora de acordar restricciones para que quienes ejerzan por voluntad propia la prostitución, dejen de hacerlo. Pero lo cierto es que su prohibición lo único que provoca es un trabajo clandestino, no regulado y con más riesgos para quienes lo ejercen. Así, es conveniente analizar las sentencias y la responsabilidad del Estado ante los organismos internacionales. Analicémoslo a partir del siguiente caso:

Cumplimiento de Compromisos internacionales asumidos por el Estado Argentino (voto del Juez Alejandro Slokar). CNCP, Sala IV, causa 1735/13 "Cañete Dario y otros s/recurso de casación”, rta.30/12/14, registro nro.3156/14. “ (...) Corresponde señalar que resultan de aplicación los compromisos internacionales asumidos en el Protocolo para Prevenir, Reprimir y Sancionar la Trata de Personas, especialmente mujeres y niños, que complementa la Convención de las Naciones Unidas contra la Delincuencia Organizada Transnacional (Ley $n^{\circ}$ 25.632, B.O. 30/8/2002, también conocida como 'Protocolo de Palermo'). (...) De otro lado, el Estado argentino se ha comprometido

16 FeluınI, Delito de tráfico de niños, Hammurabi, Bs. As., 2000, p. 147. 
en la Convención para la Eliminación de todas las formas de Discriminación contra la Mujer (CEDAW) a tomar las medidas necesarias para 'suprimir todas las formas de trata de mujeres y explotación de la prostitución de la mujer' (art. 6). Cabe recordar que la Convención Interamericana para Prevenir, Sancionar y Erradicar la Violencia contra la Mujer ba definido que: 'Se entenderá que violencia contra la mujer incluye la violencia física, sexual y psicológica: [...] que tenga lugar en la comunidad y sea perpetrada por cualquier persona y que comprende, entre otros, violación, abuso sexual, tortura, trata de personas, prostitución forzada, secuestro y acoso sexual [...], [...] que sea perpetrada o tolerada por el Estado o sus agentes, donde quiera que ocurra' (art. 2)".

En definitiva, en el presente, la pretensión del Ministerio Público Fiscal no se dirige exclusivamente a ejercer la acción penal pública y a satisfacer aquel interés estatal, sino que se reclama en cumplimiento de compromisos internacionales asumidos con el fin de evitar la responsabilidad internacional del Estado argentino.

\section{La "situación de vulnerabilidad" como justificación para la prohibición del trabajo sexual}

Con la incorporación de la definición de "situación de vulnerabilidad" en las normativas nacionales e internacionales, se excusó que la elección del trabajo sexual venía aparejada de las situaciones socioeconómicas por las que atravesaban quienes escogían el camino de la prostitución.

Retomando la noción del consentimiento de una trabajadora sexual, habría que analizar la decisión desde una postura que dignifique a la persona, considerándola una persona libre y autónoma al mismo tiempo que racional.

Opinar que la decisión de dedicarse al trabajo sexual es irracional, muestra poca confianza en que estas personas sepan lo que les conviene. Y al confesar la mayoría de ellas que deciden dedicarse al trabajo sexual porque les parece el único 
camino más viable según sus posibilidades (considerándose de esta manera una situación de vulnerabilidad por parte de los legisladores), no significa que las instituciones gubernamentales les quiten la alternativa que les pareció ser la más conveniente porque la consideran indigna. Precisamente, en una sociedad, un sector detenta pocas posibilidades, el Estado es quien debe procurarle más posibilidades, pero no cortarle las vías o caminos para alcanzar sus objetivos o lo más cercano a su plan de vida, especialmente, si lo que impide hacerlo es por una cuestión meramente de moral sexual.

Si legitimáramos el trabajo sexual considerando los encuentros sexuales como contratos entre personas racionales como sucede en algunos países del mundo, dejando de ver a la mujer como carente de capacidad para su autonomía, esto significaría el empoderamiento de estas mujeres y el respeto de su dignidad como personas. Derechos que ellas mismas están proclamando. $\mathrm{Y}$ es que, si consideramos precisamente al derecho como dinámico y adaptable según los cambios sociales, no podemos continuar penando a la prostitución (mediante normas directas o indirectas) como se hacía en 1921. Se supone que la finalidad del derecho es adaptarse al carácter dinámico de la sociedad, creando nuevos derechos y respaldos legislativos en el transcurso del cambio, para todos por igual.

Por supuesto, la situación en la oferta de servicios sexuales no es fácil de catalogar o clasificar. Es más, en muchos casos, se advierte en el trabajo sexual libre, ciertos acuerdos que muestran una falta de libertad real y, sin embargo, no se pueden catalogar como trata. Esta falta de libertad no apunta a restringir la libertad de movimiento sino más bien al manejo de los ingresos y la pelea constante entre dueños de las casas de prostitución (hoy es más común esto) y las trabajadoras sobre el servicio que se proveyó en una habitación privada. El hecho de que el trabajo sexual no se considere digno a nivel social no significa que no exista, sino que más bien se hace en la penumbra y quienes lo ofrecen no cuentan con un apoyo legal que regule su trabajo, provocando así, una verdadera situación de vulnerabilidad. 
Se ejemplifican a continuación la reflexión de los jueces y el vicio del consentimiento por parte de las trabajadoras sexuales al considerar sus acciones dentro del concepto de "situación de vulnerabilidad".

Objetivización de la persona humana. Consentimiento viciado. CNCP, Sala IV, causa nro. 400654/2008, "Taviansky, Ana Alicia y Olivera, Verónica s/ recurso de casación”, rta el 29/12/2015, reg. Nro. 2551/15. “ (...) cuando hay una situación de explotación por medio de la cual se objetiviza a la persona no puede hablarse de un consentimiento relevante a los fines de excluir la configuración del delito. Es que, se encuentra implícito en la naturaleza del bien jurídico tutelado (libertad) que no es posible otorgar consenso para ser considerado un objeto o una cosa y formar parte del mercado de bienes y servicios. Se trata de la esencia de lo humano, cuya propia explotación no puede ser consentida por el sujeto sin afectación de la condición de persona, de su libertad como bien que le es inherente (cfr. mi voto en la causa "Lamas", anteriormente citado). Por supuesto que, cuando la víctima es menor de edad, la situación es aún más delicada porque el sujeto pasivo no tiene capacidad, por su inmadurez psiquica -y la consiguiente mayor vulnerabilidad-, de comprender, en toda su extensión, el alcance de determinadas conductas".

Imposibilidad de consentir la propia explotación. CNCP, Sala IV, causa nro. FBB 5390/2013, rta el 17 de febrero de 2016, reg nro. 45/16.4. “ (...) En virtud de la actual redacción del tipo penal de trata de personas, el consentimiento de la víctima para ser ofrecido o acogido, en relación al caso en análisis, con la finalidad de ser sometido a su explotación relativa al ejercicio de la prostitución, en favor de terceros o para mantener económicamente o ser explotado económicamente por otra persona a costa de su actividad, no tendrá efectos jurídicos, por cuanto, y esto es lo sustancial en relación a los supuestos que conforman el tipo penal básico, se encuentra implícito en la naturaleza del bien jurídico tutelado (libertad) que no es posible otorgar consenso para ser considerado un objeto o una cosa y formar parte de del mercado de bienes y servicios. Se trata de la esencia 
de lo bumano, cuya propia explotación no puede ser consentida por el sujeto sin la afectación de la condición de persona, de su libertad como bien que le es inherente".

En los extractos de los fallos mencionados supra, observamos continuamente cómo los jueces justifican su postura anulando el consentimiento de prostitución en cuanto este afecta la libertad de quien lo da, haciéndose como objeto. Pero ¿qué sucede con la libertad sexual y la privacidad? ¿De qué libertad se habla si quien ofrece un servicio sexual lo hace, precisamente, por la elección que le confiere la libertad individual? En este punto podemos ver que la "libertad individual" es considerada por el Estado como violada al momento de que el sujeto decide ejercer la prostitución; y en cambio, por parte del sujeto, debido al consentimiento y a la libertad individual, es capaz de elegir dedicarse al trabajo sexual. Vemos en este sentido la contradicción de un principio constitucional según de qué lado se lo analice.

\section{Derechos constitucionales en pugna. La ponderación y la subsunción}

A raíz del análisis suscitado, haré un breve estudio en cuanto a qué principios prevalecerían entre los que se utilizan para justificar la prohibición de la prostitución y los que se proclaman para ejercerla.

Para ello primero explicaré las diferentes teorías que pueden ser utilizadas a la hora de analizar los principios jurídicos que se encuentran en conflicto y escogeré la Teoría de Moreso ${ }^{17}$ para explayar y darle una solución ficticia al tema en cuestión.

\subsection{Introducción según Moreso}

En su trabajo "Conflictos entre Principios Constitucionales", Juan José Moreso introduce el tema de una forma clara y precisa que no puede ser dejada de lado. El mismo dice:

17 Cfr. Moreso, "Conflictos entre principios constitucionales", en AAVV Neoconstitucionalismo, Madrid, Editorial Trotta, 2007. 
"La aplicación del Derecho suele concebirse como la actividad consistente en determinar la norma individual que establece una cierta consecuencia normativa para un caso individual determinado. Para tal fin, se trata de mostrar que dicho caso individual es una instancia de un caso genérico al que una norma jurídica aplicable correlaciona con esa consecuencia normativa. A dicha operación se la conoce con el nombre de subsunción. Sin embargo, cuando se trata de la aplicación de los principios constitucionales (en especial principios que establecen derechos), se argumenta, a veces, que la operación de la subsunción no es adecuada y que debe sustituirse por otra operación denominada ponderación". ${ }^{18}$

La principal teoría de Moreso, a diferencia de otros autores, es demostrar que la ponderación y la subsunción no son más que mecanismos complementarios y no contradictorios. Pero nos encargaremos de eso más adelante. Por lo pronto, introduciremos dos teorías particularistas, contrarias al pensamiento de Moreso, la de Guastini y la de Alexy.

Antes de comenzar, debo clarificar conceptualmente a lo que se denomina por "subsunción". Es la operación consistente en establecer que un caso determinado es una instancia de un caso más general. Se distinguen dos casos de subsunción: a) La individual: se afirma que un determinado caso individual es una instancia de un caso; y b) La genérica: donde un determinado caso genérico está incluido en otro caso genérico.

\subsection{Concepción guastiniana de la ponderación}

Según Guastini, la ponderación presenta tres características: La primera, se realiza entre dos principios en conflicto, cuyos supuestos de hecho se superponen parcialmente (antinomia de carácter parcial-parcial) la cual no se puede resolver. La segunda, consiste en el establecimiento de una jerarquía axiológica entre los principios en conflicto. Es una relación valorativa

18 Cfr., ibídem. 
establecida por el intérprete, mediante un juicio de valor. Y una tercera que indica que la jerarquía valorativa es establecida en su caso concreto, conformándose una jerarquía móvil, es decir que el conflicto no queda resulto de una forma estable, sino que toda solución del conflicto vale sólo para el caso concreto y es imprevisible la solución del mismo caso en un futuro.

A raíz de los principales conceptos de esta teoría, se llega a la conclusión de que la actividad de elegir entre principios en conflicto sería no controlable racionalmente porque dependerían de juicios de valor subjetivos y de propiedades de las circunstancias que no se pueden generalizar. Los principios constitucionales no pueden ser resueltos de una forma controlable racionalmente.

\subsection{Alexy y la ponderación}

Según Alexy, cuando dos principios entran en colisión uno de ellos ha de ceder frente al otro. No significa que uno de ellos sea inválido, ni que en el principio desplazado haya que introducir alguna excepción. Sucede que en determinadas circunstancias un principio cede ante el otro.

Por esta razón afirma que, en los casos concretos, los principios tienen diferente peso y el conflicto ha de resolverse según la dimensión del peso y no la de validez. Y una vez establecida la relación entre los principios en conflicto, esta permite obtener una regla para resolver el caso: la ley de colisión. Las reglas que surgen de esta ley hacen conciliables "la ponderación en el caso particular y la universalidad". Pero esta teoría tampoco comprende todas, o la mayoría, de las posibilidades genéricas que puedan darse.

\subsection{La teoría de Moreso}

Moreso afirma que la única forma de huir del particularismo consiste en concebir una reformulación ideal de los principios que tenga en cuenta todas las propiedades potencialmente relevantes. 
Si dos principios entran en colisión, se debe proceder a reformularlos de manera de establecer una jerarquía condicionada entre ellos y que sea susceptible de una universalización consistente (que no produzca conflictos en otros niveles). De esta manera, usando las ideas de Alchourrón y Bulygin, se permitirá construir una división en los casos del universo del discurso.

Esta teoría conformada por un simple sistema normativo regula de manera consistente y completa todos los casos posibles de su universo de casos. No hay más deberes derrotables porque surgen de la reformulación, de la explicitación de las asunciones implícitas, de los principios en conflicto. Dan lugar a un sistema normativo de pautas condicionales, pero inderrotables, que permite subsumir los casos individuales en algunos de los casos genéricos disponibles.

Por supuesto que pueden quedar muchas dudas acerca de si una información es o no de interés, pero se trata de dudas producidas por la textura abierta de nuestros conceptos, para resolver un caso individual deberemos primero subsumirlo en alguno de los casos genéricos. También podrá cuestionarse cuáles son las únicas propiedades relevantes y puede disputarse alguna tesis de relevancia adecuada.

La idea de la ponderación que propone Moreso, a través de teorías de Hare, explica que: por una parte, se tiene a los textos constitucionales como un conjunto de principios prima facie, que pueden entrar en conflicto entre sí y que aparecen en un contexto inarticulado (se trata la comprensión de la constitución solamente en el nivel intuitivo o Master Book según Alchourrón).

En el nivel crítico, los principios son articulados en un esquema general que da una respuesta unívoca para cada caso, puesto que cada caso individual es una instancia de un caso genérico que correlaciona el caso con una solución normativa, posibilitando la subsunción. En este nivel, la Constitución constituye un sistema normativo capaz de ofrecer respuestas 
consistentes y completas para todos los casos. Pero, como toda idealización, algunos resultados restan indeterminados, a estos casos se les deberá dar otro tipo de trato que no viene a consideración.

Idealmente el juez constitucional opera con un conjunto delimitado de propiedades relevantes que permiten correlacionar determinados casos genéricos con sus soluciones normativas. La ponderación consiste en la articulación de ese conjunto de propiedades relevantes, en la explicitación de las condiciones de aplicación que previamente era sólo implícitas.

Una vez realizado esto, la aplicación de los principios consiste en la subsunción de casos individuales en casos genéricos. Es así como Moreso, mediante su teoría, torna a la ponderación y la subsunción como dos métodos compatibles y complementarios.

\subsection{La resolución del conflicto a través de la práctica}

Una vez explicada la teoría de Moreso, vamos a intentar aplicarla a los principios constitucionales en conflicto que intentan proteger, por un lado, aquellos que penan la prostitución y, por el otro, aquellos principios que principalmente y en un contexto social y cultural diferente, la protegerían sin penarla.

Si bien los principios constitucionales involucrados cuando hablamos de prostitución y de trata son numerosos, nos limitaremos, para hacer más sencilla la explicación, a dos principales:

La libertad individual, que es la que intenta proteger la legislación por medio de la pena a la prostitución o a cualquier persona que se aprovechase de ella, entendiendo estos, que "se encuentra implícito en la naturaleza del bien jurídico tutelado (libertad) que no es posible otorgar consenso para ser considerado un objeto o una cosa y formar parte de del mercado de bienes y servicios. Se trata de la esencia de lo bumano, cuya propia explotación no puede ser consentida por el sujeto sin la afectación de la condición de persona, de su libertad como bien 
que le es inherente". ${ }^{19}$ Forma parte de la primera generación de derechos humanos y proscribe el valor constitutivo de la persona en cuanto tal, fundamento de sus deberes y derechos, conforme al cual cada uno puede decidir autónomamente sobre las cuestiones esenciales de su vida, haciéndose responsable ante la sociedad de las consecuencias de sus decisiones y de los resultados de su propia acción.

El derecho a la privacidad, proclamado en nuestra Constitución en el artículo 19: "las acciones privadas de los hombres que de ningún modo ofendan al orden y a la moral pública, ni perjudiquen a un tercero, están sólo reservadas a Dios, y exentas de la autoridad de los magistrados. Ningún habitante de la Nación será obligado a hacer lo que no manda la ley, ni privado de lo que ella no prohíbe". El cual alegan las trabajadoras sexuales a la hora de la defensa de su trabajo y el continuo pedido de una normativa digna para el reconocimiento de su trabajo.

Cabe aclarar, si bien no lo especificaremos en el ejemplo, que, a la hora de prohibir la prostitución se ve afectada la libertad individual de las trabajadoras que precisamente intenta proteger la legislación. Una acción que, además, prejuzga y discrimina el trabajo escogido por parte del Estado, impidiéndoles ejercerlo con libertad. Vemos aquí, claramente, la afectación de otros derechos constitucionales de la persona.

A partir de lo expuesto, analizaremos cuál de los dos derechos primaría según las siguientes propiedades relevantes: el consentimiento y las condiciones dignas del trabajo.

Por consentimiento entenderemos al mediado por parte de quien realiza el trabajo sexual, sin vicio de este. Por condiciones dignas se entenderá a aquellas referidas a la concepción que debe tener cualquier otro trabajo: sin tratos degradantes hacia la persona humana. En este caso específicamente, la violencia en todas sus variantes.

19 Cámara Federal de Casación Penal, Capital Federal, Ciudad Autónoma de Buenos Aires, "Marchissio, Nelssy Lidia, 12/07/2019, Id SAIJ: FA19260118. 
$\mathrm{C}=$ consentimiento $\quad \mathrm{CD}=$ condiciones dignas $\quad \mathrm{P}=$ penar Tenemos, por otro lado, las normas:

$\mathrm{N}_{1}=\mathrm{C} \& \mathrm{CD} \rightarrow \mathrm{V}_{\mathrm{p}} \quad \mathrm{N}_{2}=\neg \mathrm{C} \rightarrow \mathrm{O}_{\mathrm{p}} \quad \mathrm{N}_{3}=\neg \mathrm{CD} \rightarrow \mathrm{O}_{\mathrm{p}}$

\begin{tabular}{|c|c|c|c|c|c|}
\hline & $C$ & $C D$ & $N_{1}$ & $N_{2}$ & $N_{3}$ \\
\hline 1 & + & + & $V_{p}$ & & \\
\hline 2 & - & + & & $0_{p}$ & \\
\hline 3 & + & - & & & $0_{p}$ \\
\hline 4 & - & - & & $0_{p}$ & $0_{p}$ \\
\hline
\end{tabular}

Mediante la matriz realizada se deducirá entonces que: en los casos donde no medie consentimiento ni condiciones dignas de trabajo prevalecerá el principio de libertad individual que utilizan la legislación actual al encuadrarse en situaciones de trata de personas. Donde los jueces estarán facultados para juzgar y penar el caso en particular.

Pero si existe la libertad de consentimiento y las condiciones dignas como cualquier otro trabajo, prevalecerá la elección del sujeto de realizar trabajos sexuales y su derecho al principio de privacidad. Un campo en donde las únicas normas aplicables serán aquellas que regulen el trabajo sexual.

De esta manera, reformando los principios, convirtiéndolos en normas y sistematizándolos, se arriba a una solución de controversia de principios sin intermediar la subjetividad del juez y la irracionalidad que a veces conlleva eso.

\section{Conclusión}

En primer momento el presente trabajo versaría únicamente sobre la sección dos: la vaguedad en el concepto de "situación de vulnerabilidad". Pero para analizar el artículo 145 ter de las últimas dos modificaciones del código penal argentino, y del cual se desprende el mismo, primero debía de conocer su 
normativa antecedente, los inicios de la codificación de la trata y los motivos por los cuales habían introducido el concepto al mismo.

El análisis histórico y normativo del delito de trata me pareció tan enriquecedor y complementario a lo que se había explicado durante el curso que me pareció un desperdicio de material no relacionar los demás temas planteados y vistos en clase con el avance de la codificación del delito de trata. Así es como se extrajeron tres ejes normativos centrales para utilizarlos de ejemplo.

Inicialmente se plantearon los conceptos principales vistos en las primeras unidades sobre la distinción de ordenamiento jurídico, sistema jurídico y normas jurídicas. Así se las explicó por medio del avance paulatino de la codificación a través de las primeras promulgaciones y derogaciones de las leyes. Se vio entonces el carácter dinámico del derecho y los ordenamientos jurídicos y el estático de los sistemas. Además, se pudo dar cuenta de qué es lo que sucedía cuando con la promulgación y derogación de las normas se dejaban vacíos legales, cómo se remediaban estos.

En la segunda parte del trabajo se trató el primero de los temas que había sido considerado como eje central. Ya con una normativa más avanzada en cuando al delito mismo, se vio que, aunque no existían vacíos legales, sí eran afectadas las normas por medio de otro de los problemas del derecho y el lenguaje como era la vaguedad. Se pasó por las diferentes teorías contempladas por los doctrinarios para su subsanación y la necesidad de una normativa complementaria que no recayera puramente en la subjetividad de los jueces a la hora de dictar sentencia.

Por último, se hizo un breve análisis y comparación de los principios en pugna que versan en el delito de prostitución que fue incluido conjuntamente en el artículo de trata. Por medio de la anulación del consentimiento de quien elegía ejercer el trabajo sexual, la pena por parte del "sujeto activo" que hacía 
provecho de este y la creencia de los jueces de que quien decidía prostituirse no lo escogía inteligentemente, sino que a raíz de una "situación de vulnerabilidad", se equiparó en los últimos años la trata con la prostitución. Y es que no parece justa tal clasificación, pues, considero, como se dejó en claro en la última sección, que existe un conflicto de principios constitucionales entre quienes deciden utilizar su cuerpo como medio de trabajo y quienes intentan "proteger" a esas personas de su decisión por no considerarlas, en cierto punto, totalmente libres para tal decisión.

El breve análisis teórico y comparativo que se realizó por medio de este trabajo da cuenta la precisión y consciencia que se debe tener a la hora de utilizar el lenguaje jurídico, ya sea mediante la promulgación o derogación de nuevas normas, la ampliación de ellas o el dictado de sentencias. La imprecisión en las palabras utilizadas, la no contemplación casos generales o la carencia de reglas que definan situaciones específicas puede provocar el socavamiento de derechos o la libertad de imputados.

\section{Bibliografía}

Alchourrón, Carlos \& Bulygin, Eugenio (1971) Normative Systems. Editorial Springer Verlag. New York

Alchourrón, Carlos (1976) "Sobre el concepto de orden jurídico" en Crítica. No 23 CDMX

- (2000) "Sobre derecho y lógica" en Revista de Teoría y Filosofía del Derecho. $\mathrm{N}^{\circ} 13$. Buenos Aires.

Alonso Juan Pablo (2006) Interpretación de las normas y derecho penal. Ediciones Didot. Buenos Aires

- (2013)"Principios jurídicos implícitos y coherencia" en Doxa. Cuadernos de Filosofía del Derecho. $\mathrm{N}^{\circ} 36$. Buenos Aires. En línea en: https://doxa.ua.es/article/view/2013-n36-principiosjuridicos-implicitos-y-coherencia

- (1995) "Un caso difícil en el código civil español" en Doxa. Cuadernos de Filosofía del Derecho. No 17-18. Buenos Aires. En línea en: https://doxa.ua.es/article/view/1995-n17-18-un-casodificil-en-el-codigo-civil-espanol 
Barbitta Mariana (2008) Trata de Personas. Ed. Asociación Pensamiento Penal. Buenos Aires

Bernal Pulido, Carlos (2003) "Estructura y límites de la ponderación" en Doxa. Cuadernos de Filosofía del Derecho. $\mathrm{N}^{\circ}$ 26. Buenos Aires. En línea en: https://doxa.ua.es/article/ view/2003-n26-estructura-y-limites-de-la-ponderacion

Bulygin Eugenio (1991) "Algunas consideraciones sobre los sistemas jurídicos" en Cuadernos de Filosofía del Derecho. № 9. Buenos Aires.

Informe de la Procuraduría de Trata y Explotación De Personas, Reseña Jurisprudencial sobre casos de trata de la Cámara Federal de Casación Penal, 2016.

LeydeProfilaxis,Ley 12.331,1955.Disponibleen:https://www.argentina.gob.ar/normativa/nacional/decreto-22532-1954-195046/ texto.

Moreso, José (2010) "Conflictos entre derechos constitucionales y maneras de resolverlos" en Arbor. $\mathrm{N}^{\circ}$ 186. En línea en: http:// arbor.revistas.csic.es/index.php/arbor/article/view/1232.com

Oficina de las Naciones Unidas contra la Droga y el Delito (2013) Abuso de una situación de vulnerabilidad y otros "medios" en el contexto de la definición de trata de personas. En línea en: https://www.unodc.org/documents/human-trafficking/2016/ Abuse_of_a_position_of_vulnerability_Spanish.pdf

Pérez Porto José y Andrés Gardey (2011) Definición de ordenamiento jurídico. En línea en: https://definicion.de/ ordenamiento-juridico/

Protocolo para prevenir, reprimir y sancionar la trata de personas, especialmente mujeres y niños, que complementa la Convención de las Naciones Unidas contra la Delincuencia Organizada Trasnacional (2003). Parlemo. En línea en: https:// www.ohchr.org/Documents/ProfessionalInterest/ProtocolTraffickingInPersons_sp.pdf

Reglas de Brasilia sobre Acceso a la Justicia de las Personas en Condición de Vulnerabilidad (2008) Brasilia. En línea en: https:// www.acnur.org/fileadmin/Documentos/BDL/2009/7037.pdf

Soler Sebastián (1992) Derecho Penal Argentino. Editorial Tea. Buenos Aires. 